\title{
Sleep duration and breast cancer risk in the Breast Cancer Detection Demonstration Project follow-up cohort
}

\author{
X Qian*,1, L A Brinton ${ }^{2}$, C Schairer ${ }^{3}$ and C E Matthews ${ }^{1}$ \\ ${ }^{1}$ Nutritional Epidemiology Branch, Division of Cancer Epidemiology and Genetics, National Cancer Institute, National Institutes of \\ Health, Rockville, MD, USA; ${ }^{2}$ Hormonal and Reproductive Epidemiology Branch, Division of Cancer Epidemiology and Genetics, \\ National Cancer Institute, National Institutes of Health, Rockville, MD, USA and ${ }^{3}$ Biostatistics Branch, Division of Cancer \\ Epidemiology and Genetics, National Cancer Institute, National Institutes of Health, Rockville, MD, USA
}

Background: Short sleep has been hypothesised to increase the risk of breast cancer. However, little is known about the association between sleep and different subtypes of breast cancer defined by hormone receptor status.

Methods: Among 40013 women in the Breast Cancer Detection Demonstration Project, including 1846 incident breast cancer cases, we prospectively examined self-reported weekday and weekend sleep duration in relation to breast cancer risk. We used multivariate Cox proportional hazards regression models to estimate relative risks (RRs) and 95\% confidence intervals (Cls).

Results: We found no association between sleep and overall breast cancer. However, we observed a decreased risk of ER + PR + breast cancer (RR <6 vs 8-9h $(95 \% \mathrm{Cl}): 0.54(0.31,0.93), P$ for trend, 0.003) with shorter sleep duration.

Conclusions: Our finding does not support an association between sleep duration and overall breast cancer risk. However, the effect of sleep on different subtypes of breast cancer deserves further investigation.

Insufficient sleep has been hypothesised to increase the breast cancer risk (Blask, 2009). Mechanistic studies have shown that short sleep duration $(<6 \mathrm{~h})$ may lead to obesity (Van Cauter and Knutson, 2008), metabolic dysfunction (Gangwisch et al, 2007), chronic inflammation (Irwin et al, 2006), and altered oestrogen signalling due to suppressed melatonin production (Stevens, 2005), suggesting that an effect of sleep on breast cancer development is biologically plausible. Several epidemiological studies, including five cohort studies and two case control studies, have examined the relationship between sleep duration and breast cancer risk and produced mixed results, reporting inverse (Verkasalo et al, 2005; Kakizaki et al, 2008), positive (McElroy et al, 2006), and null (Pinheiro et al, 2006; Girschik et al, 2013; Vogtmann et al, 2013; Wu et al, 2013) associations.

Breast cancer subtypes, classified by the expression of oestrogen receptor (ER) and progesterone receptor (PR), possess distinct biological, aetiological and clinical characteristics (Chen and Colditz, 2007). There has been limited work evaluating the effects of sleep duration on risks of different subtypes of breast cancer (Girschik et al, 2013; Vogtmann et al, 2013), and no study has examined the association by PR status. In the Breast Cancer Detection Demonstration Project (BCDDP) follow-up study, we prospectively investigated sleep duration in relation to overall breast cancer risk and risks for different tumour subtypes defined by ER and PR status.

\section{MATERIALS AND METHODS}

Study population. The details of the BCDDP study have been described before (Flood et al, 2002). Briefly, between 1973 and 1980,283222 women were enrolled in the original study, and in 1979, the BCDDP follow-up study was established, and 61431 women completed the baseline questionnaire. In 1987-1989, 1993-1995 and 1995-1998, participants filled three additional questionnaires, which collected information on additional risk 
factors and self-reported cancer diagnosis. Information on sleep duration was collected in the phase 2 questionnaire (1987-1989). Of the 51690 who completed the phase 2 questionnaire, we further excluded those who reported existing cancer $(N=7766)$, and who did not report sleep duration $(N=3911)$. The final analytic cohort included 40013 women.

Breast cancer ascertainment. New incident breast cancer cases were identified through pathology reports, self-reports, as well as linkage to state cancer registries and the National Death Index. Pathology reports were sought for all self-reported cancers. In addition, about $80 \%$ of the cohort was linked to state cancer registries. Of 1846 breast cancer cases, 1358 had matching pathology reports, 279 were ascertained from state cancer registries alone without pathology reports and 209 were self-reported breast cancers with no pathology report or information from a state registry. Excluding the 209 cases that were based on self-report alone had a minimal impact on the results and we retained these cases in analysis. The status of ER and PR was obtained from cancer registries. The ER status was available for 1093 breast cancer cases and the PR status was available for 1000 breast cancer cases.

Assessment of sleep duration. Participants reported their sleep duration on weekdays and weekends separately by responding to the question 'Thinking about a typical weekday and weekend day during the past year, how many hours per day did you spend on sleeping?' We calculated weighted average of sleep duration per $24 \mathrm{~h}(($ weekday sleep duration $\times 5+$ weekend sleep duration $\times 2) / 7$ ). Weekday, weekend and average sleep duration were grouped into five categories: $<6 \mathrm{~h}, 6-<7 \mathrm{~h}, 7-<8 \mathrm{~h}, 8-<9 \mathrm{~h}$ and $\geq 9 \mathrm{~h}$. We used the largest group, $8-<9 \mathrm{~h}$, as the reference.

Statistical analysis. We used Cox proportional hazards regression models to estimate relative risks (RRs) and 95\% confidence intervals (CIs) for both overall breast cancer and subtypes of breast cancer defined by ER and PR status. Person-years of follow-up time were calculated from baseline until the date of primary cancer diagnosis, death, or the end of follow-up (31 December 2005), whichever came first. Model covariates were potential risk factors for breast cancer, including age, race, education, marital status, body-mass index (BMI), physical activity, current smoking status and pack-years smoked, number of live births, age at first birth, age at menarche, menopausal status, use of hormonal replacement therapy, use of multivitamin, use of aspirin, history of diabetes, family history of breast cancer and alcohol consumption. All the covariates were assessed at baseline. Tests for linear trend were performed by modelling a numeric value (1 through 5 ) for each sleep category. To evaluate the potential impact of reverse causation, we excluded cases diagnosed within 2 years after baseline in a sensitivity analysis. We also performed a sensitivity analysis by restricting to postmenopausal women. Additionally, we tested for interactions between sleep duration and age, education and BMI using the likelihood ratio test comparing a model with the cross-product term with one without. All analyses were performed using SAS program (SAS 9.3; SAS Institute, Cary, NC, USA).

\section{RESULTS}

At baseline, $40.1 \%$ women reported 8 to less than $9 \mathrm{~h}$ of sleep in weekdays, $10.3 \%$ reported $9 \mathrm{~h}$ or longer, while only $4.1 \%$ reported less than $6 \mathrm{~h}$. Study characteristics by weekday sleep duration are presented in Table 1 .

We did not observe an association of overall breast cancer risk with weekday, weekend or averaged sleep duration (Table 2). Adjusting for multiple covariates had little impact on the findings. The results remained null after we excluded the cases diagnosed within 2 years of follow-up, or restricting analysis to postmenopausal women (data not shown).

Table 1. Baseline characteristics of 40013 women in the Breast Cancer Detection Demonstration Project, 1987-1989

\begin{tabular}{|c|c|c|c|c|c|}
\hline & \multicolumn{5}{|c|}{ Weekday sleep duration, hour } \\
\hline & $<6$ & $6-<7$ & $7-<8$ & $8-<9$ & $9+$ \\
\hline$N(\%)$ & $1634(4.1)$ & $6714(16.8)$ & $11529(28.8)$ & $16032(40.1)$ & $4104(10.3)$ \\
\hline Age, year, mean (s.d.) & $62.9(8.9)$ & $61.2(8.0)$ & $60.5(7.5)$ & $62.2(8.0)$ & $64.3(8.9)$ \\
\hline BMI, $\mathrm{kg} \mathrm{m}^{-2}$, mean (s.d.) & $25.6(5.0)$ & $25.2(4.7)$ & $24.8(4.4)$ & $25.1(4.5)$ & $25.6(5.0)$ \\
\hline White, non-Hispanic, \% & 70.4 & 82.3 & 89.2 & 91.9 & 90.2 \\
\hline College or post-college, $\%$ & 16.9 & 22.2 & 24.1 & 21.6 & 19.2 \\
\hline Married, \% & 76.6 & 80.8 & 84.3 & 84.9 & 82.2 \\
\hline Family history of cancer, \% & 32.1 & 31.7 & 33.2 & 33.7 & 32.9 \\
\hline Current smoker, \% & 13.5 & 13.9 & 12.5 & 12.2 & 10.7 \\
\hline Nulliparous, \% & 15.0 & 14.1 & 12.4 & 13.2 & 13.8 \\
\hline Age at first live birth, $\geq 30$ years, $\%$ & 9.6 & 8.7 & 8.7 & 8.7 & 8.2 \\
\hline Age at menarche $\leqslant 12, \%$ & 45.0 & 44.9 & 43.5 & 42.0 & 40.3 \\
\hline Post-menopausal, \% & 95.4 & 92.9 & 91.2 & 92.8 & 94.4 \\
\hline HRT use, $\%$ & 54.3 & 56.4 & 57.8 & 58.4 & 60.1 \\
\hline Diabetes, \% & 7.6 & 4.7 & 3.9 & 4.2 & 7.4 \\
\hline Vigorous activity, $2+$ hours per day, $\%$ & 19.7 & 23.7 & 21.8 & 21.7 & 16 \\
\hline Multivitamin use, $\%$ & 33.4 & 35.2 & 35.7 & 35.4 & 34.9 \\
\hline Alcohol consumption, $15+\mathrm{g}$ per day, $\%$ & 5.9 & 7.7 & 9.5 & 11.3 & 10.8 \\
\hline \multicolumn{6}{|l|}{ Dietary intakes, mean (s.d.) } \\
\hline Total calories, kcal & $1180(727)$ & $1236(731)$ & $1276(731)$ & $1293(723)$ & $1338(903)$ \\
\hline Total fat, $\mathrm{g} \mathrm{kcal}^{-1}$ & $37.2(10.2)$ & $38.4(10.0)$ & $38.8(9.6)$ & $38.8(9.7)$ & $39.2(10.1)$ \\
\hline Total fiber, $\mathrm{g} \mathrm{kcal}^{-1}$ & $9.8(4.9)$ & $9.5(4.1)$ & $9.4(3.9)$ & $9.4(3.9)$ & 9.1 (3.9) \\
\hline Total fruits and vegetables, $\mathrm{g} \mathrm{kcal}^{-1}$ & $390(276)$ & $361(216)$ & 355 (202) & $353(206)$ & $337(207)$ \\
\hline
\end{tabular}


We examined the relationship between sleep duration and risks of subtypes of breast cancer (Table 3). Shorter sleep duration during weekdays was associated with reduced risks of ER+
(RR $<6 \mathrm{~h} v s 8-<9 \mathrm{~h}(95 \% \mathrm{CI}, P$ for trend): 0.53 (0.33, 0.86), 0.001), $\mathrm{PR}+(0.62(0.38,1.02), 0.003)$ and $\mathrm{ER}+\mathrm{PR}+$ breast cancer $(0.54$ $(0.31,0.93), 0.003)$. In contrast, we observed an elevated risk of

Table 2. Association between baseline sleep duration and breast cancer risk among women in the Breast Cancer Detection Demonstration Project

\section{Sleep duration, hour}

\begin{tabular}{|c|c|c|c|c|c|c|}
\hline & $<6$ & $6-<7$ & $7-<8$ & $8-<9$ & $9+$ & $P$ for trend \\
\hline \multicolumn{7}{|l|}{ Weekday } \\
\hline No. of cases/person-years & $69 / 13261$ & $326 / 55270$ & $496 / 95496$ & $769 / 131471$ & $186 / 32660$ & \\
\hline $\begin{array}{l}\text { RR }(95 \% \mathrm{Cl}) \\
\text { Age adjusted } \\
\text { Multivariate adjusted }\end{array}$ & $\begin{array}{l}0.88(0.69,1.13) \\
0.90(0.70,1.16)\end{array}$ & $\begin{array}{l}1.02(0.90,1.16) \\
1.04(0.91,1.18)\end{array}$ & $\begin{array}{l}0.91(0.81,1.01) \\
0.91(0.81,1.02)\end{array}$ & $\begin{array}{l}\text { Ref } \\
\text { Ref }\end{array}$ & $\begin{array}{l}0.95(0.81,1.12) \\
0.95(0.80,1.11)\end{array}$ & $\begin{array}{l}0.71 \\
0.95\end{array}$ \\
\hline \multicolumn{7}{|l|}{ Weekend } \\
\hline No. of cases/person-years & $44 / 8820$ & $176 / 33022$ & $357 / 68452$ & $809 / 138171$ & $327 / 56268$ & \\
\hline $\begin{array}{l}\text { RR }(95 \% \mathrm{Cl}) \\
\text { Age adjusted } \\
\text { Multivariate adjusted }\end{array}$ & $\begin{array}{l}0.82(0.61,1.11) \\
0.86(0.63,1.17)\end{array}$ & $\begin{array}{l}0.90(0.76,1.05) \\
0.92(0.78,1.08)\end{array}$ & $\begin{array}{l}0.89(0.79,1.01) \\
0.91(0.80,1.03)\end{array}$ & $\begin{array}{l}\text { Ref } \\
\text { Ref }\end{array}$ & $\begin{array}{l}0.99(0.87,1.13) \\
0.99(0.87,1.12)\end{array}$ & $\begin{array}{l}0.04 \\
0.12\end{array}$ \\
\hline \multicolumn{7}{|l|}{ Weighted average } \\
\hline No. of cases/person-years & $45 / 9167$ & $267 / 45524$ & $449 / 85072$ & $631 / 108873$ & $161 / 27081$ & \\
\hline $\begin{array}{l}\text { RR }(95 \% \mathrm{Cl}) \\
\text { Age adjusted } \\
\text { Multivariate adjusted }\end{array}$ & $\begin{array}{l}0.85(0.63,1.15) \\
0.87(0.64,1.18)\end{array}$ & $\begin{array}{l}1.03(0.89,1.19) \\
1.04(0.90,1.20)\end{array}$ & $\begin{array}{l}0.93(0.82,1.05) \\
0.93(0.82,1.05)\end{array}$ & $\begin{array}{l}\text { Ref } \\
\text { Ref }\end{array}$ & $\begin{array}{l}1.00(0.84,1.19) \\
1.00(0.84,1.19)\end{array}$ & $\begin{array}{l}0.58 \\
0.71\end{array}$ \\
\hline \multicolumn{7}{|c|}{ Weekday sleep, excluding cases diagnosed within the first 2 years of follow-up } \\
\hline No. of cases/person-years & $57 / 13244$ & $257 / 55162$ & $402 / 95384$ & $624 / 131279$ & $149 / 32600$ & \\
\hline $\begin{array}{l}\text { RR }(95 \% \mathrm{Cl}) \\
\text { Age adjusted } \\
\text { Multivariate adjusted }\end{array}$ & $\begin{array}{l}0.90(0.69,1.18) \\
0.93(0.70,1.22)\end{array}$ & $\begin{array}{l}0.99(0.86,1.14) \\
1.01(0.87,1.17)\end{array}$ & $\begin{array}{l}0.90(0.79,1.02) \\
0.90(0.80,1.03)\end{array}$ & $\begin{array}{l}\text { Ref } \\
\text { Ref }\end{array}$ & $\begin{array}{l}0.95(0.79,1.13) \\
0.95(0.79,1.13)\end{array}$ & $\begin{array}{l}0.59 \\
0.80\end{array}$ \\
\hline \multicolumn{7}{|c|}{ 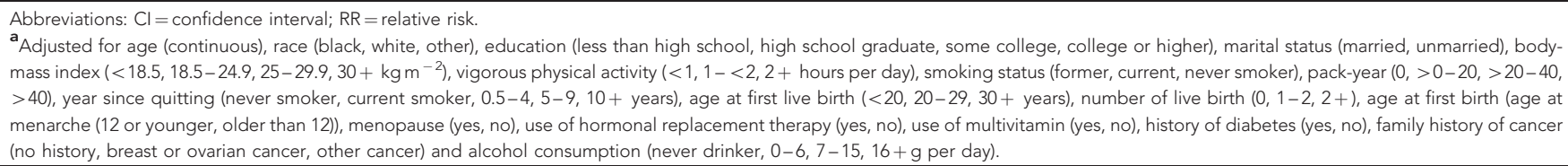 } \\
\hline
\end{tabular}

Table 3. Association between baseline weekday sleep duration and breast cancer risk among women in the Breast Cancer Detection Demonstration Project, by hormonal receptor status of breast cancer

\begin{tabular}{|c|c|c|c|c|c|c|}
\hline & \multicolumn{5}{|c|}{ Weekday sleep duration, hour } & \multirow{2}{*}{$P$ for trend } \\
\hline Breast cancer subtype & $<6$ & $6-<7$ & $7-<8$ & $8-<9$ & $9+$ & \\
\hline \multicolumn{7}{|l|}{ ER +} \\
\hline $\begin{array}{l}\text { No. of cases/person-years } \\
\text { Multivariate } \mathrm{RR}^{\mathrm{a}}(95 \% \mathrm{Cl})\end{array}$ & $\begin{array}{c}18 / 13106 \\
0.53(0.33,0.86)\end{array}$ & $\begin{array}{c}124 / 54537 \\
0.83(0.68,1.02)\end{array}$ & $\begin{array}{c}221 / 94491 \\
0.82(0.69,0.97)\end{array}$ & $\begin{array}{c}\text { 378/130 } 102 \\
\operatorname{Ref}\end{array}$ & $\begin{array}{c}98 / 32387 \\
1.04(0.83,1.30)\end{array}$ & 0.001 \\
\hline \multicolumn{7}{|l|}{ ER - } \\
\hline $\begin{array}{l}\text { No. of cases } \\
\text { Multivariate RRa }(95 \% \mathrm{Cl})\end{array}$ & $\begin{array}{c}14 / 13106 \\
2.12(1.18,3.82)\end{array}$ & $\begin{array}{c}25 / 54537 \\
0.84(0.53,1.33)\end{array}$ & $\begin{array}{c}55 / 94491 \\
1.02(0.72,1.45)\end{array}$ & $\begin{array}{c}\text { 73/130 } 102 \\
\text { Ref }\end{array}$ & $\begin{array}{c}21 / 32387 \\
1.17(0.72,1.91)\end{array}$ & 0.65 \\
\hline \multicolumn{7}{|l|}{ PR +} \\
\hline $\begin{array}{l}\text { No. of cases/person-years } \\
\text { Multivariate } \operatorname{RR}^{\mathrm{a}}(95 \% \mathrm{Cl})\end{array}$ & $\begin{array}{c}17 / 13101 \\
0.62(0.38,1.02)\end{array}$ & $\begin{array}{c}103 / 54526 \\
0.85(0.68,1.07)\end{array}$ & $\begin{array}{c}182 / 94448 \\
0.83(0.69,1.00)\end{array}$ & $\begin{array}{l}\text { 307/130 } 040 \\
\text { Ref }\end{array}$ & $\begin{array}{c}86 / 32368 \\
1.12(0.88,1.42)\end{array}$ & 0.003 \\
\hline \multicolumn{7}{|l|}{ PR - } \\
\hline $\begin{array}{l}\text { No. of cases } \\
\text { Multivariate RR }(95 \% \mathrm{Cl})\end{array}$ & $\begin{array}{c}14 / 13101 \\
1.21(0.69,2.12) \\
\end{array}$ & $\begin{array}{c}42 / 54526 \\
0.81(0.57,1.15) \\
\end{array}$ & $\begin{array}{c}82 / 94448 \\
0.89(0.67,1.18) \\
\end{array}$ & $\begin{array}{c}\text { 128/130 } 040 \\
\text { Ref }\end{array}$ & $\begin{array}{c}28 / 32368 \\
0.89(0.59,1.35) \\
\end{array}$ & 0.73 \\
\hline \multicolumn{7}{|l|}{$\mathrm{ER}+\mathrm{PR}+$} \\
\hline $\begin{array}{l}\text { No. of cases/person-years } \\
\text { Multivariate RR }(95 \% \mathrm{Cl})\end{array}$ & $\begin{array}{c}14 / 13101 \\
0.54(0.31,0.93)\end{array}$ & $\begin{array}{c}98 / 54519 \\
0.86(0.68,1.08)\end{array}$ & $\begin{array}{c}171 / 94438 \\
0.82(0.68,1.00)\end{array}$ & $\begin{array}{l}292 / 130024 \\
\operatorname{Ref}\end{array}$ & $\begin{array}{c}80 / 32357 \\
1.10(0.85,1.41)\end{array}$ & 0.003 \\
\hline \multicolumn{7}{|l|}{ ER - PR - } \\
\hline $\begin{array}{l}\text { No. of cases } \\
\text { Multivariate } \operatorname{RR}^{\mathrm{a}}(95 \% \mathrm{Cl})\end{array}$ & $\begin{array}{c}11 / 13101 \\
2.07(1.07,4.02)\end{array}$ & $\begin{array}{c}18 / 54519 \\
0.77(0.45,1.30)\end{array}$ & $\begin{array}{c}43 / 94438 \\
1.03(0.69,1.52)\end{array}$ & $\begin{array}{l}58 / 130024 \\
\text { Ref }\end{array}$ & $\begin{array}{c}17 / 32357 \\
1.19(0.69,2.04)\end{array}$ & 0.89 \\
\hline \multicolumn{7}{|c|}{$\begin{array}{l}\text { Abbreviations: } \mathrm{Cl}=\text { confidence interval; } E R=\text { oestrogen receptor; } \mathrm{PR}=\text { progesterone receptor; } \mathrm{RR}=\text { relative risk. } \\
\text { a Adjusted for age (continuous), race (black, white, other), education (less than high school, high school graduate, some college, college or higher), marital status (married, unmarried), body- } \\
\text { mass index }\left(<18.5,18.5-24.9,25-29.9,30+\mathrm{kg} \mathrm{m}^{-2}\right) \text {, vigorous physical activity }(<1,1-<2,2+\text { hours per day), smoking status (former, current, never smoker), pack-year }(0,>0-20,>20-40, \\
>40) \text {, year since quitting (never smoker, current smoker, } 0.5-4,5-9,10+\text { years), age at first live birth }(<20,20-29,30+\text { years), number of live birth }(0,1-2,2+) \text {, age at menarche } \\
\text { (12 or younger, older than 12), menopause (yes, no), use of hormonal replacement therapy (yes, no), use of multivitamin (yes, no), history of diabetes (yes, no), family history of cancer } \\
\text { (no history, breast or ovarian cancer, other cancer) and alcohol consumption (never drinker, } 0-6,7-15,16+g \text { per day). }\end{array}$} \\
\hline
\end{tabular}


ER - $(2.12(1.18,3.82))$ and ER - PR - subtypes $(2.07(1.07,4.02))$ among women reporting $<6 \mathrm{~h}$ sleep, although the trend for associations was not statistically significant. Similar results are observed for weekend sleep duration (Supplementary Table 1) and the average of weekday and weekend sleep (Supplementary Table 2). We found no interaction between sleep and age, education, race, BMI or use of menopausal hormone therapy in relation to breast cancer risk (data not shown).

\section{DISCUSSION}

In this cohort of predominantly postmenopausal women, we found no association between sleep duration and overall breast cancer risk. Our findings for subtypes of breast cancer suggested a decreased risk of ER- and PR-positive breast cancer and an increased risk of ER-negative breast cancer among women who reported $<6 \mathrm{~h}$ of sleep.

Previous studies on sleep duration and overall breast cancer risk generally reported weak or null associations. Although some earlier investigations found an inverse relationship (Verkasalo et al, 2005; Kakizaki et al, 2008), a similar association has not been observed in the more recent, larger studies. The two largest prospective studies on this topic conducted in the Nurses' Health Study (NHS) (Pinheiro et al, 2006) and the Women's Health Initiative (WHI) (Vogtmann et al, 2013), both found no association between sleep duration and overall breast cancer risk. Moreover, two recent meta-analyses reported no evidence for an effect of sleep duration on overall breast cancer risk (Qin et al, 2013; Yang et al, 2014).

Our findings of different effects of short sleep duration on different hormone receptor subtypes of breast cancer are intriguing, although the results may be due to chance alone and need to be confirmed by future studies. Only two studies examined sleep duration and breast cancer risk by ER status. A case-control study in Australia reported that sleep duration on workday or nonworkday was not associated with either ER + or ER - breast cancer (Girschik et al, 2013). In the WHI study, no association between sleep duration and ER - tumour was observed. However, a weak trend of positive association $(P=0.02)$ with $\mathrm{ER}+$ tumour was noted, although risk estimates were not significant for the individual sleep categories $\left(\mathrm{RR} \leqslant 5 \mathrm{~h} v \mathrm{~s}_{7 \mathrm{~h}}(95 \% \mathrm{CI})\right.$ : 0.92 (0.80, 1.05)) (Vogtmann et al, 2013).

According to the melatonin hypothesis, sleep deficiency and circadian disruption reduce the level of melatonin, a hormone that modulates both oestrogen metabolism and ER-mediated signalling pathway and is considered to have an anticarcinogenic effect against breast cancer (Cos et al, 2006). Therefore, short sleep has been hypothesised to increase the risk of ER + breast cancer. We found no support for this hypothesis and if anything, we observed a reduced risk of ER + breast cancer among women who reported short sleep. In contrast, we found an elevated risk of ER - breast cancer among short sleepers, which suggests the possibility of oestrogen-independent effects of short sleep on breast cancer risk. Circadian clock regulates a wide range of physiological functions, including energy metabolism, immune activity, DNA repair and cell proliferation (Blask, 2009). Insufficient sleep as a form of circadian disruption may impact breast cancer risk through its influence on these pathways. Future studies are needed to identify biological mechanisms that may link sleep and circadian disturbances with cancer.

One of the limitations of this study is that sleep duration was self-reported and prone to measurement error. Previous studies showed that self-reported and measured sleep duration are only moderately correlated and people with short sleep are more likely to over-report their sleep duration than are people with longer sleep (Lauderdale et al, 2008). This would lead to misclassification of the main exposure and may result in an attenuation of observed associations for the short sleep categories. Additionally, we only had one-time measurement of sleep, and were not able to capture change in in sleep duration and evaluate its effect on breast cancer risk. We also lacked information on other important aspects of sleep that may influence breast cancer risk, such as sleep quality, snoring, sleep disorder, sleeping pill use, chronotype, napping habit and light at night. Moreover, we did not have information on occupational history, and night shift work might confound the observed associations. Finally, we had small number of cases of ER - and PR - tumours, and therefore we have limited statistical power in our analysis of these subtypes. There are several notable strengths of this study. Its prospective design decreases the likelihood of differential recall bias, a serious limitation of casecontrol studies. Additionally, the large cohort with a fairly long follow-up time allowed us to conduct a sensitivity analysis by excluding cases diagnosed with the first 2 years, reducing the possibility for reverse causation due to undiagnosed breast cancer.

In summary, our finding does not support an association between sleep duration and overall breast cancer risk. However, the effect of sleep on different subtypes of breast cancer deserves further investigation.

\section{REFERENCES}

Blask DE (2009) Melatonin, sleep disturbance and cancer risk. Sleep Med Rev 13(4): 257-264.

Chen WY, Colditz GA (2007) Risk factors and hormone-receptor status: epidemiology, risk-prediction models and treatment implications for breast cancer. Nat Clin Pract Oncol 4(7): 415-423.

Cos S, Gonzalez A, Martinez-Campa C, Mediavilla MD, Alonso-Gonzalez C, Sanchez-Barcelo EJ (2006) Estrogen-signaling pathway: a link between breast cancer and melatonin oncostatic actions. Cancer Detect Prev 30(2): $118-128$.

Flood A, Velie EM, Chaterjee N, Subar AF, Thompson FE, Lacey Jr JV, Schairer C, Troisi R, Schatzkin A (2002) Fruit and vegetable intakes and the risk of colorectal cancer in the Breast Cancer Detection Demonstration Project follow-up cohort. Am J Clin Nutr 75(5): 936-943.

Gangwisch JE, Heymsfield SB, Boden-Albala B, Buijs RM, Kreier F, Pickering TG, Rundle AG, Zammit GK, Malaspina D (2007) Sleep duration as a risk factor for diabetes incidence in a large U.S. sample. Sleep 30(12): 1667-1673.

Girschik J, Heyworth J, Fritschi L (2013) Self-reported sleep duration, sleep quality, and breast cancer risk in a population-based case-control study. Am J Epidemiol 177(4): 316-327.

Irwin MR, Wang M, Campomayor CO, Collado-Hidalgo A, Cole S (2006) Sleep deprivation and activation of morning levels of cellular and genomic markers of inflammation. Arch Intern Med 166(16): 1756-1762.

Kakizaki M, Kuriyama S, Sone T, Ohmori-Matsuda K, Hozawa A, Nakaya N, Fukudo S, Tsuji I (2008) Sleep duration and the risk of breast cancer: the Ohsaki Cohort Study. Br J Cancer 99(9): 1502-1505.

Lauderdale DS, Knutson KL, Yan LL, Liu K, Rathouz PJ (2008) Self-reported and measured sleep duration: how similar are they? Epidemiology 19(6): 838-845.

McElroy JA, Newcomb PA, Titus-Ernstoff L, Trentham-Dietz A, Hampton JM, Egan KM (2006) Duration of sleep and breast cancer risk in a large population-based case-control study. J Sleep Res 15(3): 241-249.

Pinheiro SP, Schernhammer ES, Tworoger SS, Michels KB (2006) A prospective study on habitual duration of sleep and incidence of breast cancer in a large cohort of women. Cancer Res 66(10): 5521-5525.

Qin Y, Zhou Y, Zhang X, Wei X, He J (2013) Sleep duration and breast cancer risk: A meta-analysis of observational studies. Int J Cancer 134: 1166-1173.

Stevens RG (2005) Circadian disruption and breast cancer: from melatonin to clock genes. Epidemiology 16(2): 254-258.

Van Cauter E, Knutson KL (2008) Sleep and the epidemic of obesity in children and adults. Eur J Endocrinol 159(Suppl 1): S59-S66. 
Verkasalo PK, Lillberg K, Stevens RG, Hublin C, Partinen M, Koskenvuo M, Kaprio J (2005) Sleep duration and breast cancer: a prospective cohort study. Cancer Res 65(20): 9595-9600.

Vogtmann E, Levitan EB, Hale L, Shikany JM, Shah NA, Endeshaw Y, Lewis CE, Manson JE, Chlebowski RT (2013) Association between sleep and breast cancer incidence among postmenopausal women in the women's health initiative. Sleep 36(10): 1437-1444.
Wu AH, Stanczyk FZ, Wang R, Koh WP, Yuan JM, Yu MC (2013) Sleep duration, spot urinary 6-sulfatoxymelatonin levels and risk of breast cancer among Chinese women in Singapore. Int J Cancer 132(4): 891-896.

Yang WS, Deng Q, Fan WY, Wang WY, Wang X (2014) Light exposure at night, sleep duration, melatonin, and breast cancer: a dose-response analysis of observational studies. Eur J Cancer Prev 23(4): 269-276.

Supplementary Information accompanies this paper on British Journal of Cancer website (http://www.nature.com/bjc) 